\title{
Disengagement: A partial solution to the annuity puzzle
}

\author{
Hazel Bateman \\ School of Risk and Actuarial Studies, University of New South Wales, Australia \\ Christine Eckert \\ Centre for the Study of Choice and School of Marketing, University of Technology, Sydney, Australia \\ John Geweke \\ Centre for the Study of Choice, University of Technology, Sydney, Australia \\ Fedor Iskhakov \\ Centre for the Study of Choice, University of Technology, Sydney, Australia \\ Jordan Louviere \\ Centre for the Study of Choice, University of Technology, Sydney, Australia \\ Stephen Satchell \\ Trinity College, University of Cambridge and University of Sydney, Australia \\ Susan Thorp \\ Centre for the Study of Choice and Finance Group, University of Technology, Sydney, Australia
}

March 20, 2013

Acknowledgements. The authors acknowledge financial support under ARC DP1093842, generous assistance with the development and implementation of the internet survey from PureProfile and the staff of the Centre for the Study of Choice, University of Technology Sydney; and excellent research assistance from Rebecca McKibbin, Mariya Thieviasingham and Edward Wei. The Chair of Finance and Superannuation (Thorp), UTS, receives support from the Sydney Financial Forum (through Colonial First State Global Asset Management), the NSW Government, the Association of Superannuation Funds of Australia (ASFA), the Industry Superannuation Network (ISN), and the Paul Woolley Centre for the Study of Capital Market Dysfunctionality, UTS.

Email addresses: Bateman: h.bateman@unsw.edu.au; Eckert: christine.eckert@uts.edu.au; Geweke: john.geweke@uts.edu.au; Iskhakov: fedor.iskhakov@uts.edu.au; Louviere: jordan.louviere@uts.edu.au; Satchell: ses11@cam.ac.uk; Thorp: susan.thorp@uts.edu.au 


\begin{abstract}
This research studies whether individuals make choices consistent with expected utility maximization in allocating wealth between a lifetime annuity and a phased withdrawal account at retirement. The paper describes the construction and administration of a discrete choice experiment to 854 respondents approaching retirement. The experiment finds overall rates of inconsistency with the predictions of the standard CRRA utility model of roughly $50 \%$, and variation in consistency rates depending on the characteristics of the respondents. Individuals with poor numeracy and with low engagement with the choice task, as measured by scores on a task-specific recall quiz, are more likely to increase allocations to the phased withdrawal as the risk of exhausting it increases. Individuals with higher scores on tests of financial capability and with knowledge of retirement income products are more likely to score high on the engagement measure, but capability and knowledge do not have independent effects on consistent choice rates. Results suggest that initiatives to improve specific product knowledge and to help individuals engage with decumulation decisions could be a partial solution to the annuity puzzle.
\end{abstract}

JEL classification: G23; G28; D14

Key words: discrete choice; retirement incomes; household finance; annuities; financial literacy; 


\section{Introduction}

Most members of defined benefit (DB) pension plans enjoy a natural continuity in income between work and retirement via pre-set annuity payments. By contrast, members of defined contribution (DC) plans who want to insure against outliving their income must give up lump sum savings in exchange for a lifetime annuity while still keeping some liquid assets to cover uninsured events.

Despite strong theoretical support for lifetime annuity purchase (Yaari 1965; Davidoff et al. 2005; Horneff et al. 2007), the weak global demand for voluntary life annuities is a continuing puzzle (Mitchell et al. 2011). The US and Australia, for example, both operate private retirement savings schemes yet very few convert retirement accumulations to lifetime annuities: only around $1 \%$ of US $401(\mathrm{k})$ plan retirees offered a life annuity actually purchase one (EBRI, 2011) and sales of life annuities in Australia stand at around 100 policies annually in a market with several million retirees (Plan for Life 2012). The negligible demand for life annuities is more surprising in Australia where virtually all workers save into mandatory individual DC (superannuation) accounts and do not receive earnings-linked social security payments.

Academic research has not settled on a definitive explanation for the annuity puzzle. Theoretical studies cannot explain why even partial annuitization is rare $\mathrm{1}^{1}$ and when empirical studies show some demand for annuities it is often where the annuity is the default (Bütler and Teppa 2007; Benartzi et al. 2012)2 2 $^{2}$ More recently, research has turned to behavioral or psychological explanations, surveyed in Brown (2008) and Benartzi et al. (2012). Behavioral explanations for a lack of interest in annuities include mental accounting and loss aversion (Hu and Scott 2007), susceptibility to information framing (Agnew et al. 2008; Brown et al. 2008; Cappelletti et al. 2011; Beshears et al. 2012) and complexity (Brown et al. 2011). Here we expand on the contributions of both conventional and behavioral research by testing how disengagement with the retirement benefit decision affects annuity choice.

\footnotetext{
${ }^{1}$ Extensions to standard lifecycle models attribute low consumer interest in lifetime annuities to pricing issues (Mitchell et al. 1999), crowding out (Dushi and Webb 2004), bequests (Bernheim 1991), intra family risk sharing (Brown and Poterba 2001), demand for liquidity for uncertain health expenses (Turra and Mitchell 2008; Peijnenburg et al. 2010) and the option value of delay (Kingston and Thorp 2005; Milevsky and Young 2007). However, Inkmann et al. (2011) do find theoretical support for low annuity demand for specific combinations of preference parameters.

${ }^{2}$ For example, using Swiss pension fund data Bütler and Teppa (2007) a 90\% annuity take up rate (73\% full and $17 \%$ partial) where the annuity is the default, compared with only $10 \%$ under a lump sum default.
} 
Much previous research assumes that ordinary people know what retirement benefit products are available and understand how they work. However, a preliminary survey we conducted showed scant product awareness and minimal understanding of the main insurance features of income streams: for example, only one third of respondents had heard of a life annuity, with only $20 \%$ and $8 \%$ aware of its longevity and income guarantee characteristics. Respondents showed similar ignorance of other retirement income products such as phased withdrawals ${ }^{3}$

A lack of understanding is not surprising. A life annuity is a complex, one-in-a-lifetime product, unfamiliar to most pre-retirees. The recent switch to DC plans means that there has been limited opportunity for social learning among the current generation (Bernheim 2002). Unlike other major financial decisions, such as house purchases, older generations have little experience with managing an accumulation lump sum and cannot give advice. Further, the retirement benefit decision involves high stakes (often the household's largest non-housing asset) and is typically made only once, often irreversibly, which prevents people learning from past experience (Beshears et al 2008). In addition, purchasing retirement products from a menu is a difficult financial decision usually needing immediate action but having consequences well into the future (Beshears et al. 2008). The relationship between both financial capability and financial outcomes (Lusardi and Mitchell 2009, 2011; Gerardi et al. 2010; Guiso and Jappelli 2008), and specific product knowledge and retirement saving decisions (Gustman et al. 2012; Cappelletti et al. 2011), is well established. Moreover, Brown et al. (2011) confirm that people with low financial literacy are particularly confused by life annuities. It is likely that most ordinary members of DC plans have not learned what they really need to know about life annuities or other retirement benefit products by the time they are ready to retire.

Motivated by the complexity of life annuities, we investigate the impact of plan member interest and specific product understanding on the quality of retirement benefit choices, and particularly, the demand for annuities. We design and implement a discrete choice experiment on benefit decisions through a survey panel of 854 near-to-retirement DC plan members from Australia. Each survey respondent chooses the percentage of financial wealth to allocate to two retirement income streams: a liquid phased withdrawal account invested in risky assets and a life

\footnotetext{
${ }^{3}$ The survey was conducted on a representative sample of 920 Australian pre-retiree superannuation (pension) fund members aged 50-74 and was designed to collect information about consumer awareness and understanding of retirement income products available in the Australian market.
} 
annuity with or without a guarantee period. Respondents make two sets of pairwise allocations (phased withdrawal v. life annuity, then phased withdrawal v. period certain annuity) at four risk levels. The risk they confront is the chance of running out of money in the phased withdrawal account before the end of life, and consequently having to live on a reduced income. Income from the annuities is guaranteed but income from the phased withdrawal may be exhausted. The result is two sequences of four wealth allocations revealing respondents' changing preferences for guaranteed income and liquidity as the risk of exhausting the liquid account increases.

We approach the annuity decision differently from previous studies. First, we do not presume that individuals approaching retirement know and understand retirement benefit products. Instead, we show respondents a clear explanation and comparison of the alternative products in terms of five common features. Second, rather than offering an 'all or nothing' annuitization decision, we let people explore a continuum of partial annuitization options. Respondents can trade-off the benefits of a non-annuitized product (phased withdrawal), such as access to liquid balances and continued exposure to investment risk, against the benefits of a constant, lifetime income stream (life annuity) ${ }^{4}$ Third, under this experimental design, where reductions in income due to exhausting resources are significant and permanent, and respondents allocate all financial wealth at retirement, risk aversion over income should be significant. Hence we can evaluate whether the sequence of retirement wealth allocation decisions are consistent with some implications of CRRA utility maximization. A simple indicator of consistency is whether we see respondents choosing no less longevity insurance as the probability of exhausting liquid balances before the end of life increases. This condition tests whether respondents grasp the main insurance feature of the annuity.

Finally, in our estimation of decision consistency, we specifically measure and take account of engagement with the experimental task. In any choice experiment, data quality depends on respondents' 'real-time' interest in the task at hand. It is likely that the choices of individuals who are uninterested distort results. Many experiments use monetary rewards to create interest and align incentives (Camerer and Hogarth, 1999) but few embed direct tests of task engagement. Here we introduce an individual task engagement measure: we collect scores from a short recall

\footnotetext{
${ }^{4}$ In our experiment respondents choose from a vector of allocations to each product that increase from $0 \%$ to $100 \%$ in increments of 5 percentage points. Beshears et al (2012) provide a similar setup with increments of 25 percentage points.
} 
quiz that tests knowledge of the five common features of the retirement products in the allocation experiment:5 The recall quiz reviews survey-specific information about the annuities and phased withdrawal that respondents should read just before the task. Quiz scores measure whether the respondent is engaging with the choice task, and at the same time show how capable they are of comparing the products effectively. If a respondent cannot recall the vital features of the products, they are likely to be disengaged and uninformed, and less likely to meet the consistency condition.

This experiment allows us to assess the effect of disengagement on annuitization decisions. In particular, we show how a lack of engagement and the resultant lack of specific product knowledge limits people's ability to manage retirement income risk and consequently distorts annuity choice. We also investigate how pre-existing numeracy and financial literacy help, and to what extent. Overall the results show that pre-existing financial capability increases task engagement, as measured by the recall quiz score, but consistent choices are directly explained only by task engagement and numeracy. Engagement can help plan members learn the insurance features of income stream products, so increasing their ability to perceive and manage retirement risk.

Section 2 sets out a simple model of retirement wealth allocation used to design our discrete choice experiment. Simulations using this model imply that certain allocation sequences should not be observed for CRRA utility maximizers. In Section 3 we discuss the design and implementation of the on-line experiment, including the experimental task, the recall quiz designed to test task engagement and questions that collect data on financial capability, commercial product knowledge, health, longevity expectations, planning and demographics. Section 4 presents our econometric model and findings. The final section reviews findings. It outlines tentative conclusions about importance of task engagement in experimental settings, the links between engagement and pre-existing financial capability, and the importance of both product-specific knowledge and quantitative skills in decumulation decisions.

\footnotetext{
${ }^{5}$ This approach is informed by the idea of an Instructional Manipulation Check (IMC) as developed in Oppenheimer et al. (2009).
} 


\section{Analytical framework}

This theoretical model sets out a simplified retirement wealth allocation problem which guides the development of the choice experiment. We demonstrate by simulation that certain sequences of allocations to the phased withdrawal are excluded for utility maximizing CRRA agents with plausible preference parameters.

\subsection{Theoretical model of retirement wealth allocation}

Consider an individual who reaches retirement with a stock of liquid wealth $w$ which is measured net of the amounts set aside for bequests. At retirement this wealth is shared between a pair of retirement benefit products, forming a portfolio $\left(p_{A} \in[0,1],\left(1-p_{A}\right)=p_{\tilde{R}}\right)$, where $p_{A} w$ is

allocated to a life annuity and $p_{\tilde{R}} w$ to a risky phased withdrawal account with return $\tilde{R}_{t}$. The chosen portfolio is fixed for the remainder of life, and the only choices made after retirement are consumption and savings.

The timing of events is the following. At the beginning of the period $t$ the return $\tilde{R}_{t}$ on the risky asset is realized and total resources $M_{t}$ composed of capital income, annuity payment $y$ and public pension payment $p_{t}$ are determined according to

$$
M_{t}=\tilde{R}_{t}\left(M_{t-1}-c_{t-1}\right)+y+p_{t}
$$

Then consumption $c_{t}=\left[0, M_{t}\right]$ and savings $\left(M_{t}-c_{t}\right)$ are chosen by the individual, and consumption takes place. Each period $t$ is concluded with the realization of survival process, conditional on which the problem is repeated in the next period $t+1$.

We assume that the choice of $p_{A}$ is made instantly at retirement, and the first period $t=1$ starts immediately afterwards, which makes it special in two respects. First, we assume that initial wealth $w$ already includes the realized random return on previous period's net wealth holding. Second, we assume that the individual is alive at $t=1$ and thus the first annuity payment is paid out with certainty.

Let $\pi_{t}$ denote the probability of survival from time period $t$ to time period $t+1$. The annuity 
is fairly priced, therefore we have

$$
y=\frac{p_{A} w}{\sum_{t=1}^{T}(1+r)^{1-t} \prod_{\tau=1}^{t-1} \pi_{\tau}}
$$

where $r$ is the risk free interest rate.

Given the assumptions on period $t=1$, immediately after retirement total resources are given by $M_{1}=p_{\tilde{R}_{t}} w+y$. The individual chooses optimal consumption $c_{t}$ in every time period until death so as to maximize expected lifetime utility $V_{1}\left(M_{1}\right)$ given by the following recursive formula:

$$
V_{t}\left(M_{t}\right)=\max _{0 \leq c_{t} \leq M_{t}}\left[u\left(c_{t}\right)+\beta \pi_{t} E V_{t+1}\left(M_{t+1}\right)\right]
$$

where $u\left(c_{t}\right)$ is the instantaneous utility of consumption, and next period's total liquid resources $M_{t+1}$ are given by the intertemporal budget constraint (1).

The public pension (in this context, the 'Age Pension') is an important part of the retirement income system and provides inflation and longevity insurance. It offers a means-tested safety net payout that is not dependent on an individual's labor market history. We include it in the budget equation (1). Assuming no labor income, the Age Pension benefit $p_{t}$ depends on the previous period's wealth $\left(M_{t-1}-c_{t-1}\right)$ and annuity income $y$ in the current period. Appendix A describes the Australian institutional settings which we adapt for the current model $[6]$

\section{$2.2 \quad$ Illustration using CRRA utility}

Under constant relative risk aversion (CRRA) utility of the form $u\left(c_{t}\right)=\left(c_{t}^{1-\lambda}-1\right) /(1-\lambda)$ and reasonable parameter values, $(\lambda=0.5, \ldots, 3$ and $\beta=0.90,0.95)$ optimal allocations of retirement wealth generated by the model for a range of individuals are presented in Figure 17 Other parameters are set out in Table 1. Simulation results show that the optimal allocations to $p_{\tilde{R}}$ are monotonically decreasing as the return $\tilde{R}_{t}$ declines through four location changes. (These

\footnotetext{
${ }^{6}$ In Australia, the Age Pension payment is means-tested but not earnings-linked and is paid to around $76 \%$ of age-eligible residents (Harmer 2009). Eligibility for the Australian public pension depends on age, residency status, marital status, home-ownership, income and assets. In this study, the experimental allocation task is framed as an individual decision and respondents are screened for other eligibility factors. Age Pension treatments in the experiments depend on intended retirement age (no pension payment is included for early retirees) and wealth (pension payments in choice sets are adjusted by means-test tapers applied to respondents' wealth). We do not condition on home-ownership since $72 \%$ of respondents say they own their home.

${ }^{7}$ The model was solved numerically using the endogenous grid point method (Carroll, 2006)
} 
are chosen to create a range of probabilities of exhausting the phased withdrawal before the end of life for the experiment. They are set out in Table 1.) In cases of very low risk aversion, the optimal allocation is at the $100 \%$ boundary. The result of lower allocations to $p_{\tilde{R}}$ as the return declines holds over a wide range of wealth levels $(\$ 50,000-\$ 1$ million), when the retiree is eligible for the public Age Pension (Figure 1, A-D) and when they are not (E). When the individual does not receive the the public Age Pension, allocations to $p_{\tilde{R}}$ decline at faster rates. Means-testing tapers encourage eligible retirees to substitute private annuity income for the public annuity (public Age Pension) at higher levels of wealth. This simple model serves to benchmark income and risk levels in the choice sets presented to respondents in the on-line experimental task. 

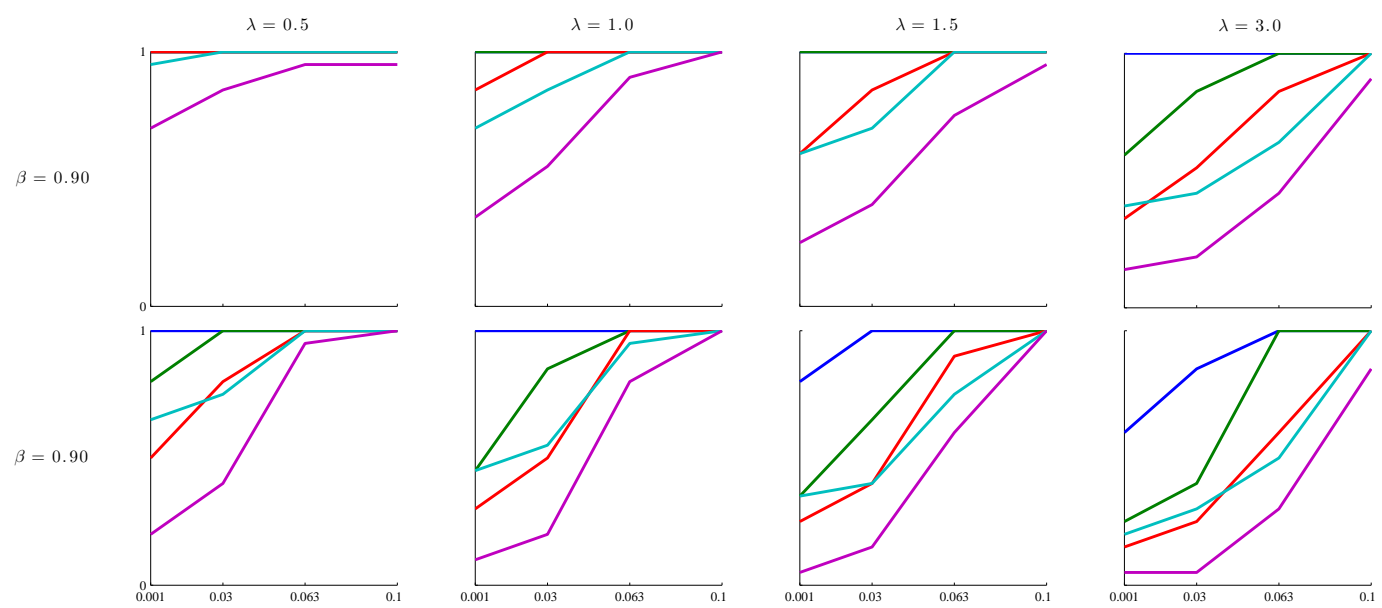

Expected gross returns of risky product, $E[\tilde{R}]$
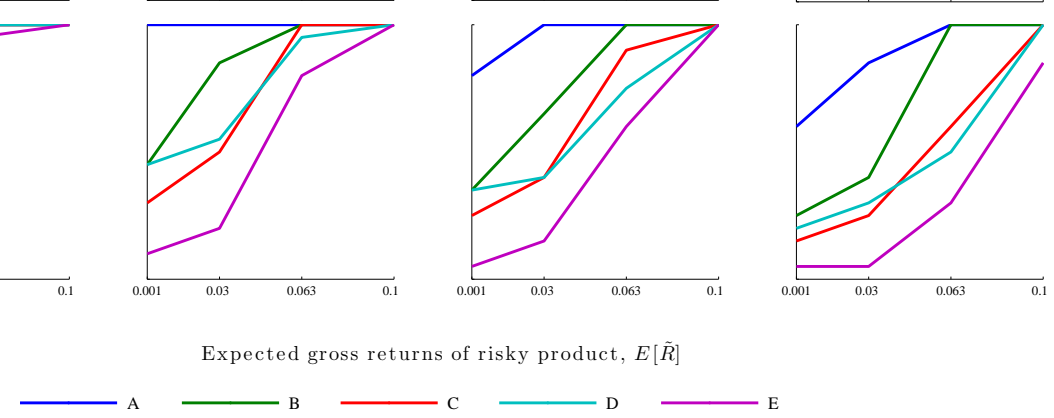

Figure 1: Optimal allocations to risky phased withdrawal account.

Graph shows optimal proportions of wealth at retirement allocated to the risky phased withdrawal account for CRRA investor with relative risk aversion parameter of $\lambda$ and discount factor of $\beta=0.9$, as the location of the risky asset return distribution changes (horizontal axis). The remaining proportion is allocated to a life annuity. The investor is a male aged 65 at retirement with expected survival prospects consistent with cohort life tables for Australia; see Table 1 for parameter values. Lines show A: initial wealth $\$ 50,000$, in the presence of the Age Pension; B: initial wealth $\$ 125,000$, in the presence of the Age Pension; C: initial wealth $\$ 250,000$, in the presence of the Age Pension; D: initial wealth $\$ 1$ million, in the presence of the Age Pension; and E: in the absence of the Age Pension, for any level of initial wealth.

\section{$3 \quad$ Experiment and survey structure}

We conducted a discrete choice experiment to evaluate the consistency of retirement benefit choices with predictions of the CRRA model 8 Pension plan data on individuals' retirement income product purchases could not be used for this evaluation, since revealed preference market data may show actual choices made from among a set of alternatives and under a single expectation of investment returns and longevity prospects, but not the same decision repeated at different settings. While choice experiments do provide a setting to test such a proposition, a difficulty of any experiment involving a hypothetical allocation of the entire stock of a respondent's retirement wealth, is to construct an effective incentive scheme. We cannot force respondents to risk their whole retirement savings, and small incentives that protect against real losses are unlikely to have the planned effect. Further, it is not at all clear how to offer an incentive scheme that is compatible with the liquidity versus longevity risk trade-off on which

\footnotetext{
${ }^{8}$ The full dynamic survey is available at http://survey.confirmit.com/ penalty $\backslash z @\{\}$ wix/p1912625505. aspx and a static version at http://www.censoc.uts.edu.au/ penalty $\backslash z @\{\} r e s e a r c h a r e a s / \backslash p e n a l t y \backslash z @$ \{\}Super_Screenshots.pdf
} 
the choices pivot.

The experimental task was included in a five part on-line survey that collects an array of information about each respondent. The first part filtered ineligible respondents and sorted eligible respondents into treatment groups (described below). The second part was the retirement benefit choice experiment, followed by a recall quiz for testing task engagement. The fourth and fifth parts collected demographic and retirement planning data, and measures of financial and system knowledge respectively. In this section we first describe the choice experiment and then the remainder of the survey instrument.

\subsection{Choice task and consistency criteria}

The discrete choice experiment asks respondents to divide their retirement wealth between pairs of retirement benefit products in two settings. There are three products. The first product,

$A$ (an immediate life annuity), provided a level real lifetime income stream. The annuity $A$ was fairly priced at a risk-free real interest rate of $2 \%$ and at improved mortality probabilities from the most recent population life tables (Australian Government Actuary 2009). The second product $B$ (a phased withdrawal) creates an income stream as withdrawals from an account invested in a diversified portfolio of assets yielding an uncertain return. The account balance of $B$ is of uncertain duration but unlike $A$ is available for discretionary withdrawals. The third product $C$ makes guaranteed income payments for 15 years to the purchaser and/or beneficiaries and after that makes payments as long as the purchaser is alive (Product $C$ is product $A$ with a 15 year guarantee). Respondents made two sets of allocations, by comparing $A$ with $B$ at different risk levels (and then $C$ with $B$ ), and chose from a set of allocations to each product that increased from $0 \%$ to $100 \%$ in steps of 5 percentage points. The outcome of each experimental choice task for each respondent can be written as a percentage allocation to product $B$.

\subsubsection{Variation in risk of exhausting phased withdrawal}

When comparing products, each respondent is shown four probabilities of running out of money in the phased withdrawal product before the end of life. These probabilities depend on the returns distribution of the underlying investment, the rate at which income is drawn from the 
account each period and the probability of survival $[9$ We vary the probabilities by changing the rate of return on the underlying investment, using four log-normal distributions of gross returns $\tilde{R}$ which are indexed by $i=1,2,3,4$. Table 1 shows the parameters of these distributions. The last column in Table 1 shows corresponding probabilities of exhausting $B$ before the end of life, calculated using the most recent current survival probabilities $\pi_{t}$ (Australian Government Actuary 2009), and assuming level annual income draws from $B$ at the same rate as the rate of annuity payments 10

Table 1: Alternative risk level parameters, Male, Age 65

\begin{tabular}{cccccccc}
\hline $\begin{array}{c}\text { Risk } \\
\text { level } i\end{array}$ & \multicolumn{2}{c}{ Log-normal parameters } & \multicolumn{2}{c}{$\tilde{R}$} & \multicolumn{2}{c}{ Males, Age 65 } & Probability of exhausting \\
$\mu_{i}$ & $\sigma_{i}$ & $E(\tilde{R}-1)$ & s.d. & $\pi_{t}$ & rate of income draw & income from B \\
\hline 1 & 0.0861 & 0.1357 & 0.100 & 0.15 & 0.953 & 0.067 & 0.10 \\
\hline 2 & 0.0512 & 0.1404 & 0.063 & 0.15 & 0.953 & 0.067 & 0.25 \\
\hline 3 & 0.0191 & 0.1449 & 0.030 & 0.15 & 0.953 & 0.067 & 0.50 \\
\hline 4 & -0.0111 & 0.1492 & 0.001 & 0.15 & 0.953 & 0.067 & 0.75 \\
\hline \hline
\end{tabular}

\subsubsection{Framing of the allocation decision}

Choices are framed as decisions over guaranteed and/or risky (labelled 'expected') annual income streams where the probability of exhausting the risky income stream varies over four levels from 'very low' (1 in 10) to 'very high' (3 in 4). Every choice set displays the 'expected' and 'guaranteed' minimum lifetime income associated with any selection. The guaranteed component of income depends on allocations to $A(C)$ and any public Age Pension entitlement. The 'expected' income is the sum of the guaranteed component and an annual draw-down from $B$, where the rate of payout is the same as the rate of payout from $A(C)$. The draw of income from $B$ had to be assumed so that the retirement benefit products could be described in terms of levels of annual incomes and integrated with public Age Pension payments. Making the spending rate from $B$ equal to the rate of annuity payout means that 'expected' income stream is proportional to financial wealth at retirement.

At each step in the choice sequence, respondents see the 'expected' and guaranteed income,

\footnotetext{
${ }^{9}$ For the experiment, the probability of exhausting this account is computed using the approximation method of Huang et al. (2004).

${ }^{10}$ The lognormal distributions were used for calibration only and we did not provide information to respondents about specific returns distributions or expect them to infer one.
} 
and the liquid wealth available for contingencies or unintentional bequest implied by their allocation. However in each step of the sequence, the risk of a permanently lower income rises. On seeing an increasing probability of exhausting the phased withdrawal account at the same expected income, and hence an increasing risk of falling to a lower lifetime income, individuals should allocate no more to $B$. The analysis in Section 4 evaluates whether each respondent's sequence of percentage allocations to $B$ do not increase as the risk of exhausting income from that product rises. We label sequences of allocations that conform to this criterion as 'consistent'.

\subsubsection{Experiment instructions and design}

The experiment section of the on-line survey begins with instructions, reproduced in Appendix $\mathrm{B}$, that set out a simplified retirement income plan. Respondents were asked to allocate their retirement wealth (observed elsewhere in the survey) using what is known as a 'product configurator' (e.g., Kamis, Koufaris and Stern, 2008), a slider that was manipulated by the respondent's cursor.

The experiment used a within and between subjects design. Subjects were sorted into 16 treatments groups: first by gender (2 groups), since annuity payments are lower for women than for men because of longer life expectancy; second by predictions of financial wealth at retirement (based on self-reported net worth), to allow for public Age Pension means-testing (4 groups: $\$ 50 \mathrm{~K} ; \$ 125 \mathrm{~K} ; \$ 250 \mathrm{~K} ; \$ 1$ million) and to ensure that the task did not deviate too much from experience; and finally by intended retirement age (2 groups: guaranteed incomes of those retiring before public pension eligibility age did not include Age Pension payments). Each participant then allocated their predicted retirement wealth in eight settings, the Cartesian product of the four risk levels indicated in Table 1 and two pairs of products, $A$ v. $B$ and $C$ v. $B$.

Before they saw the choice sets, respondents read descriptions of products in terms of five common features, Who provides this product?; How much income will I receive?; How long do payments last?; What happens if I die? and Can I withdraw a lump sum for unforeseen events or changes of plans:11 Commercial product names were never mentioned. After viewing three

\footnotetext{
${ }^{11}$ We adapted wording from the Australian Securities and Investment Commission MoneySmart website https://www.moneysmart.gov.au/\penalty $\backslash \mathbf{z}\{\{\}$ superannuation-and-retirement/ $\backslash$ penalty $\backslash z @\{\}$ income-sources-in-retirement/penalty $\backslash z @\{\}$ income-from-super/annuities and
} 
example choice sets, respondents were able to explore the continuum of product combinations by clicking on the configurator, monitoring changes in expected and guaranteed income and access to liquidity at different allocation weights, before making a final choice. A 50:50 allocation was the default position of the configurator slider in all settings. Each choice scenario also showed the probability that income from the phased withdrawal $B$ would be exhausted before the end of life, over four levels. Figure 2 illustrates a choice set at the lowest probability of exhausting income from $B$.

Table 2 displays the expected and guaranteed incomes for a $25 \%, 50 \%$ and $75 \%$ allocation to $B$ for Males with and without the public Age Pension. Guaranteed income levels are comprised of the fairly priced annuity stream 'purchased' at each allocation and any public Age Pension for which the respondent was eligible. For example, a fairly priced life annuity for a 60 year old male, (improved life expectancy of 88.64 years) pays $\$ 5.84$ p.a. for each $\$ 100$ of wealth allocated. If $50 \%$ of a $\$ 50,000$ retirement accumulation is allocated to the life annuity $A$, guaranteed income without the Age Pension is $\$ 1,460$ p.a. which explains the entry in row 3, column 5 of Table 1 . Expected income is the sum of the $\$ 1,460$ income from $A$ and another $\$ 1,460$ from the allocation of remaining wealth to $B$. The income amount for $B$ assumes that income is withdrawn at a rate equal to the annuity payout, that is at $5.84 \%$ p.a. of the wealth allocated to $B$.

\subsection{Sample and survey context}

We selected a random sample of 854 respondents from those members of the PureProfile online panel of over 600,000 Australians who had at least one current pension plan account, were between the ages of 50 and 64 in 2011 and who satisfied the residency requirements for the public Age Pension. Under Australia's Superannuation Guarantee, almost all workers between 18 and 65 years of age participate in the mandatory retirement savings system, mostly as members of DC, privately managed, funds. Benefits are preserved until at least age 55 (rising to age 60 for many in our sample) at which time plan members must decide how to use their accumulations. Retirees who purchase income stream products accrue tax concessions over those who take lump sum payments, and approximately half of preserved savings are transferred to income streams 

Choice Set 1 of 4 :
Now imagine you are at retirement and you have $\$ 1$ million of super and savings to use to purchase either Product A or Product B, or a combination of
both.

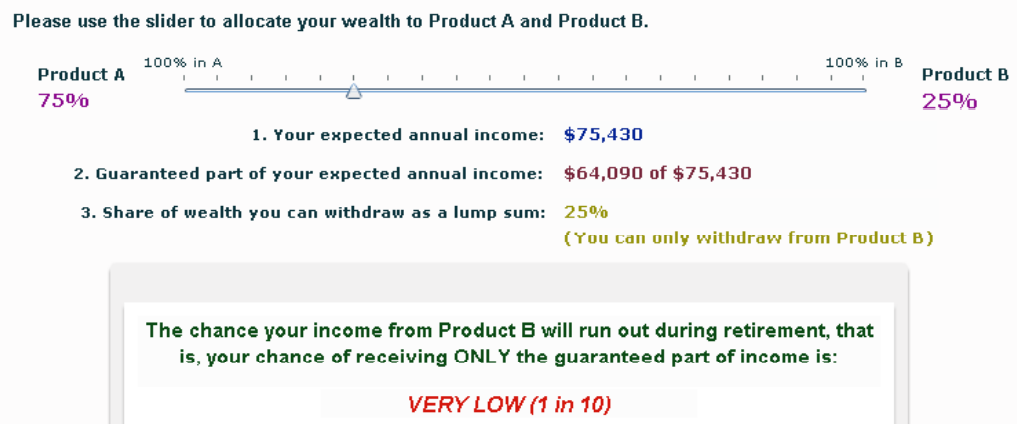

- Hover over "Product $A$ " and "Product $B$ " for more information

Figure 2: Illustrative choice set, Males with $\$ 1$ million of retirement wealth, Age Pension eligible, lowest risk of exhausting $B$.

(albeit mostly non-annuitized phased withdrawal products). It follows that the choice task is a simplified, hypothetical version of a decision that respondents will have to make in the near future.

The first part of the survey collected demographic data (age, marital status, work status, occupation, industry/business, education, income) including the information needed to filter and separate respondents into the 16 treatment groups. From this information we constructed a dichotomous covariate (Gender) coded as 1 for males and 0 for females, a dichotomous covariate (Early retirement intention) coded as 1 for respondents intending to retire before pension age (age 65) and 0 otherwise. Respondents answered detailed questions on asset and liability holdings and intentional bequests. From these we constructed a polychotomous covariate for retirement wealth (\$000) (Wealth) taking values of 50 for net worth excluding the family home of less than $\$ 50,000,125$ for net worth in the range of $\$ 50,000$ to less than $\$ 200,000,250$ for net worth in 
Table 2: Indicative expected and guaranteed annual incomes in the discrete choice experiment: Males, comparing $A$ and $B$.

\begin{tabular}{|c|c|c|c|c|c|c|}
\hline & \multicolumn{6}{|c|}{ Allocation to Phased Withdrawal $B$} \\
\hline & \multicolumn{3}{|c|}{ Age Pension included } & \multicolumn{3}{|c|}{ No Age Pension } \\
\hline & $25 \%$ & $50 \%$ & $75 \%$ & $25 \%$ & $50 \%$ & $75 \%$ \\
\hline \multicolumn{7}{|l|}{ Financial Wealth $\$ 50 \mathrm{~K}$} \\
\hline Expected income (\$p.a.) & 22,340 & 22,340 & 22,340 & 2,920 & 2,920 & 2,920 \\
\hline Guaranteed income (\$p.a.) & 21,490 & 20,650 & 19,810 & 2,190 & 1,460 & 730 \\
\hline \multicolumn{7}{|l|}{ Financial Wealth $\$ 125 \mathrm{~K}$} \\
\hline Expected income (\$p.a.) & 27,400 & 27,400 & 27,400 & 7,300 & 7,300 & 7,300 \\
\hline Guaranteed income (\$p.a.) & 25,290 & 23,180 & 21,070 & 5,470 & 3,650 & 1,820 \\
\hline \multicolumn{7}{|l|}{ Financial Wealth $\$ 250 \mathrm{~K}$} \\
\hline Expected income (\$p.a.) & 34,560 & 33,860 & 33,150 & 14,590 & 14,590 & 14,590 \\
\hline Guaranteed income (\$p.a.) & 31,630 & 27,400 & 23,180 & 10,940 & 7,300 & 3,650 \\
\hline \multicolumn{7}{|l|}{ Financial Wealth $\$ 1,000 \mathrm{~K}$} \\
\hline Expected income (\$p.a.) & 75,430 & 72,360 & 69,290 & 58,370 & 58,370 & 58,370 \\
\hline Guaranteed income (\$p.a.) & 64,090 & 49,680 & 35,270 & 43,780 & 29,190 & 14,590 \\
\hline
\end{tabular}

the range of $\$ 200,000$ to less than $\$ 600,000$ and 1000 for higher. The second part of the survey was the retirement benefits choice task (including product descriptions, configurator explanation and the choice scenarios).

In the third survey section, respondents answered 18 true/false questions that tested their recall of the five features of $A, B$ and $C$ presented in the retirement benefit product descriptions. ${ }^{12}$ From these answers we calculated the proportion of correct answers( Quiz). We believe this is a reasonable measure of engagement with the choice task for the following reasons: first, to answer correctly respondents must read and understand the experiment-specific product descriptions; second, $A, B$ and $C$ are not labeled with the names of existing commercial income stream products, so respondents cannot answer the quiz correctly from their ex ante 'real world' product knowledge without reading the descriptions; and third, we know from pilot survey re-

\footnotetext{
${ }^{12}$ The quiz required that respondents check all of the following that apply to each of the products $A, B$ and $C$ : 1. I can withdraw a lump sum for unforseen events; 2. If I die, payments stop; 3. I will receive a regular income for as long as I live; 4. My account balance will fluctuate with financial markets; 5 . Payments are guaranteed to me or my beneficiaries for the first 15 years; 6 . None of these apply. The answer to question 2 for $C$ is ambiguous so those responses were omitted from the total score.
} 
sponses that awareness of retirement benefit products is very low 13 In Section 4 we show that not paying attention to the descriptions of $A, B$ and $C$ makes consistent choices less likely.

Following the recall quiz, respondents answered questions on retirement planning and expectations, bequest intentions, precautionary savings intentions, plans to liquidate housing wealth, mortality and morbidity expectations and current quality of life. The questions from this section that are included our final model are detailed in Appendix C. From these answers we constructed a continuous covariate (Subjective life expectancy) measuring the deviation of the respondent's subjective life expectancy from that predicted by the Australian Life Tables. Positive values indicate optimistic subjective survival expectations. We also constructed a polychotomous covariate for the financial aspects of retirement planning (Retirement financial planning) taking the values $0,1,2, \ldots, 6$ as the level of planning increased from 'I haven't thought at all about what I will need for retirement' to 'I have a firm idea of what I need and I'm on track to reach it'. As well we computed each respondent's mean score across the five dimensions of quality of life (mobility, self care, usual activities, pain and anxiety/depression) where 1 is very low and 3 is very high quality (Quality of Life).

The final part of the survey consists of questions measuring numeracy and financial literacy skills, as well as self-assessed knowledge of finance, use of financial advice, trust in financial service providers and awareness and knowledge of existing retirement income products ${ }^{14}$ We construct covariates (Numeracy, Basic Literacy and Sophisticated Literacy) as the proportion of correct responses to each group of questions. Self-assessed financial literacy (Self-assessed Literacy) is measured on a scale of 1-7 with 7 meaning very high understanding. Finally, we create a covariate (Commercial product knowledge) as the proportion of correct answers in a set of questions testing awareness of and detailed knowledge of real world retirement income products. (See Appendix C.)

\footnotetext{
${ }^{13}$ Other possible proxies for task engagement, such as the number of times respondents 'clicked' to explore the configurator or the time spent completing the task, are likely to be noisier measures. For example, a person who understands products A and B well, perceives the risk of ruin accurately and who sees the income information may click few times on the allocation scale, having clear preferences. Similarly, time can be confounded by random distractions. Our recall quiz is similar to the Instructional Manipulation Check (IMC) of Oppenheimer et al. (2009), where satisficing survey participants who are not following instructions are identified.

${ }^{14}$ The three numeracy questions and four financial literacy questions, detailed in Appendix B, are drawn from Lipkus et al. (2001) and Lusardi and Mitchell (2009). Numeracy questions test proportions, percentages and simple probability; two basic financial literacy questions test interest and inflation and two sophisticated financial literacy questions test diversification.
} 
From this information we selected numeracy, tested and subjectively assessed financial literacy, product knowledge, current quality of life, subjective survival expectations, financial aspects of retirement planning and the treatment indicators (gender, wealth and retirement intentions) as covariates in the model to be discussed in Section 4. The selection was based on preliminary estimations confirming that other potentially important covariates including age, formal education, marital status, occupation, health expectations, bequest intentions, precautionary savings intentions, detailed knowledge of the public pension and plans to leave the workforce, were not relevant.

\section{Econometric model and findings}

We investigate the rate at which respondents choose consistently with standard expected utility model predictions, as a function of task engagement and the covariates just described. The 854 complete responses are made up of four allocations between products $A$ and $B$ and four between $C$ and $B$, making 6,832 in total. The first panel in Table 3 shows the average percentage allocation to phased withdrawal $B$ over life annuity $A$ for each of the 16 treatment groups as the risk of exhausting $B$ rose from 'very low' to 'very high'. The second panel shows average percentage allocation to $B$ over life annuity with guarantee, $C$. 
Table 3: Average Percentage of Retirement Wealth Allocated to Phased Withdrawal

\begin{tabular}{|c|c|c|c|c|c|c|c|c|c|c|c|c|c|c|c|c|}
\hline \multirow[b]{3}{*}{ Risk level } & \multicolumn{16}{|c|}{ Financial Wealth at Retirement } \\
\hline & \multicolumn{4}{|c|}{$\$ 50 \mathrm{~K}$} & \multicolumn{4}{|c|}{$\$ 125 \mathrm{~K}$} & \multicolumn{4}{|c|}{$\$ 250 \mathrm{~K}$} & \multicolumn{4}{|c|}{$\$ 1000 \mathrm{~K}$} \\
\hline & 1 & 2 & 3 & 4 & 1 & 2 & 3 & 4 & 1 & 2 & 3 & 4 & 1 & 2 & 3 & 4 \\
\hline $\begin{array}{l}A \text { versus } B \\
M a l e\end{array}$ & & & & & & & & & & & & & & & & \\
\hline Retire $<65$ years & 48 & 51 & 45 & 44 & 50 & 41 & 37 & 40 & 52 & 51 & 46 & 40 & 54 & 53 & 44 & 43 \\
\hline $\begin{array}{l}\text { Retire } \geq 65 \text { years } \\
\text { Female }\end{array}$ & 49 & 49 & 41 & 44 & 53 & 54 & 45 & 44 & 49 & 48 & 39 & 38 & 46 & 46 & 45 & 42 \\
\hline Retire $<65$ years & 45 & 50 & 44 & 44 & 46 & 51 & 40 & 41 & 54 & 48 & 42 & 35 & 55 & 52 & 48 & 51 \\
\hline Retire $\geq 65$ years & 51 & 52 & 49 & 42 & 52 & 52 & 46 & 45 & 52 & 47 & 49 & 40 & 54 & 54 & 53 & 52 \\
\hline $\begin{array}{l}C \text { versus } B \\
M a l e\end{array}$ & & & & & & & & & & & & & & & & \\
\hline Retire $<65$ years & 48 & 45 & 37 & 38 & 54 & 51 & 45 & 45 & 51 & 50 & 39 & 37 & 55 & 54 & 48 & 44 \\
\hline $\begin{array}{l}\text { Retire } \geq 65 \text { years } \\
\text { Female }\end{array}$ & 45 & 47 & 42 & 40 & 50 & 49 & 43 & 37 & 52 & 46 & 37 & 35 & 49 & 49 & 44 & 46 \\
\hline Retire $<65$ years & 49 & 43 & 46 & 41 & 50 & 46 & 43 & 37 & 53 & 55 & 45 & 44 & 57 & 47 & 45 & 42 \\
\hline Retire $\geq 65$ years & 51 & 51 & 47 & 43 & 52 & 51 & 43 & 42 & 49 & 49 & 43 & 43 & 53 & 53 & 49 & 48 \\
\hline $\begin{array}{l}\text { No. respondents } \\
\text { Male }\end{array}$ & & & & & & & & & & & & & & & & \\
\hline Retire $<65$ years & & & 1 & & & & & & & & & & & & 7 & \\
\hline $\begin{array}{l}\text { Retire } \geq 65 \text { years } \\
\text { Female }\end{array}$ & & & 3 & & & & & & & & & & & & 0 & \\
\hline Retire $<65$ years & & & 5 & & & & & & & & & & & & 8 & \\
\hline Retire $\geq 65$ years & & & 15 & & & & & & & & & & & & 8 & \\
\hline
\end{tabular}

Notes: Top panel shows average percentage of wealth allocated by respondents in each treatment group to $B$ over $A$ at risk of exhausting income from $B$ of (1) 1 in 10, (2) 1 in 4, (3) 1 in 2 to (4) 3 in 4 . Product $A$ is an immediate indexed lifetime annuity; product $B$ is a phased withdrawal. Second panel shows average percentage of wealth allocated to $B$ over $C$ as risk increases. Product $C$ is an immediate indexed lifetime annuity with a 15 year guarantee period. Lower panel shows number of respondents in each treatment group. 
Table 3 shows generally decreasing average allocations to $B$ as risk rises, consistent with risk aversion. Declines are more regular for the early retirement treatment groups (Retire $<65)$. For these respondents, choice set displays of 'guaranteed incomes' did not include the public Age Pension and consequently income reductions due to exhausting $B$ were more conspicuous.

\subsection{Inconsistency rates}

We assume independence across respondents in the analysis. Each respondent $r$ makes an allocation to $A$ and $B(C$ and $B)$ at each risk level $i=1,2,3,4$. We index the pairwise product comparisons as $f=1,2$. For each respondent $r$, decisions over risk levels $i$ in comparison sets $f$ result in two $4 \times 1$ vectors of allocations to product $B$. If these vectors are non-increasing in the percentage allocated to $B$ as $i$ rises, the respondent recognizes increasing risk and conforms with our simple CRRA utility model. Respondents who do not conform may be missing or ignoring one main benefit of purchasing an annuity. We treat the dichotomous outcome of violating this condition as a random variable where $P\left(v_{r}^{(f)}=1\right)=p^{(f)}$, for $f=1,2$. We label this the independent response (IR) model.

The first column of Table 4 presents the estimates of $p^{(f)}$ for all respondents using only counts of consistency: around one half of respondents increased their allocation to the phased withdrawal (product $B$ ) as risk increased in both the $A$ v. $B$ and $C$ v. $B$ allocation tasks (the weak condition). However, the condition that respondents choose a non-increasing percentage allocation to $B$ does not rule out respondents who always choose 50:50 allocations. The second column of Table 4 presents estimates of $p^{(f)}$ where $v_{r}^{(f)}=1$ is assigned to respondents who violate the condition or who do not move the slider away from the default at all (the strong condition). The standard error of each element in Table 4 is about 0.017 so the rates of inconsistency at $f=2$ are significantly lower than at $f=1$. Respondents may have become more familiar with the experimental task in the second round of choices and consequently made fewer errors. They may also have preferred $C$ to $A$.

In complex financial choices attentiveness and engagement are critical. Subjects bring their own personal financial capability, expectations and other demographic characteristics to the choice experiment. Of these, gender, wealth and retirement intentions are used here to sort respondents into treatment groups. During the task, respondents will also be more or less 
Table 4: Probabilities of inconsistent allocation sequences in sets $A-B$ and $C-B$

\begin{tabular}{lcc}
\hline & Weak condition & Strong condition \\
$p^{(1)}$ & 0.555 & 0.717 \\
$p^{(2)}$ & 0.484 & 0.645 \\
\hline \hline
\end{tabular}

Note: Table shows estimate of IR probability of inconsistent allocations. The weak condition for conformity is satisfied where the percentage of wealth allocated to $B$ never increases as $i$ rises. The strong condition adds the requirement that respondents move the slider at least once, either to explore the choice set or make an allocation.

engaged, attending to instructions and information, maintaining attention and thinking through the choices with varying intensities. Pre-determined financial capability could influence choices both directly and indirectly: directly by enabling 'consistent' choice and indirectly by motivating task engagement which then promotes consistent choices. Engagement is likely to be affected by capability but is also endogenous to the choice task itself and hence potentially a predictor of inconsistency.

We propose a triangular structure to model choices. The structure has two components: the first determines endogenous task engagement conditional on a vector of pre-determined respondent characteristics and the second estimates the probability of inconsistency conditional on the vector of pre-determined characteristics and the measure of endogenous task engagement. We call this the conditionally independent response model (CIR) where the probability of inconsistent choices is independent of $r$ and $f$ but conditional on treatments and covariates.

We estimate the following recursive system of equations:

$$
\begin{aligned}
Q u i z_{r} & =\boldsymbol{\beta}_{\mathbf{1}}^{\prime} \boldsymbol{x}_{\boldsymbol{r}}+\epsilon_{r} \\
\operatorname{Pr}\left(v_{r}=1\right) & =\Lambda\left(\boldsymbol{\beta}_{\mathbf{2}}^{\prime} \boldsymbol{x}_{\boldsymbol{r}}+\psi Q u i z_{r}\right) \\
\Lambda(z) & =\frac{\exp (z)}{1+\exp (z)}
\end{aligned}
$$

where Quiz $_{r}$ is the proportion of the recall quiz questions answered correctly by respondent $r$ (i.e., our measure of task engagement); $\boldsymbol{x}_{\boldsymbol{r}}$ is a vector of pre-determined variables measuring numeracy, financial product knowledge, financial literacy, subjective financial understanding, retirement finance planning, subjective life expectancy, quality of life, and treatment group 
variables including gender, intended retirement age and wealth; and $\epsilon_{r}$ is an independent error term 15

Estimation results show that pre-existing financial capability and several measures of attitudes and expectations predict task engagement (as proxied by success in the recall quiz Quiz $z_{r}$ ). Table 5 reports OLS estimation of equation $4^{16}$ Preliminary analysis showed that the mean score for engagement was $73 \%$ with a minimum of $29 \%$ and maximum of $100 \%$ with a standard deviation of $18 \%$. Using the estimates from Table 5 , we find that two additional correct answers in the numeracy questions or basic financial literacy (interest and inflation) questions increased the engagement score by about 8 percentage points and by slightly less for the sophisticated literacy (diversification) questions. A 50\% increase in correct commercial product knowledge or a score in the upper half of the retirement financial planning range also accounts for a similar increase in engagement. An intention to retire before age 65 increases engagement by 2 percentage points; a 20 year increase in subjective life expectancy has a similar impact. On the other hand, males, respondents with higher reported wealth, those currently enjoying a high quality of life and those with a higher level of self-assessed financial literacy were significantly less engaged.

Table 5: Estimated coefficients for Equation 4

\begin{tabular}{lccc}
\hline Dependent variable: Quiz & Coef & S.E & p-value \\
\hline Gender & $-0.028^{* *}$ & 0.012 & 0.017 \\
Wealth & $-0.00004^{* *}$ & 0.000 & 0.016 \\
Early retirement intention & $0.020^{*}$ & 0.012 & 0.087 \\
Numeracy & $0.113^{* *}$ & 0.018 & 0.000 \\
Basic financial literacy & $0.074^{* *}$ & 0.020 & 0.000 \\
Sophisticated financial literacy & $0.064^{* *}$ & 0.017 & 0.000 \\
Self-assessed financial literacy & $-0.010^{* *}$ & 0.005 & 0.038 \\
Commercial product knowledge & $0.167^{* *}$ & 0.037 & 0.000 \\
Retirement financial planning & $0.017^{* *}$ & 0.003 & 0.000 \\
Quality of life & $-0.056^{*}$ & 0.022 & 0.012 \\
Subjective life expectancy & $0.001^{*}$ & 0.001 & 0.077 \\
Constant & $0.703^{* *}$ & 0.064 & 0.000 \\
& & & \\
R-squared & & & 0.229 \\
\hline \hline
\end{tabular}

Notes: ** Statistically significant at the $5 \%$ level. * Statistically significant at the $10 \%$ level. Sample size: 854 .

\footnotetext{
${ }^{15}$ The assumption underlying equation 5 is that the random utility of irrational choice is $U\left(v_{r}=1\right)=\boldsymbol{\beta}_{\mathbf{2}}^{\prime} \boldsymbol{x}_{\boldsymbol{r}}+$ $\psi Q u i z_{r}+\nu_{r}$ where $\nu_{r}$ is i.i.d. Gumbel distributed with scale equal to one, and is independent of $\epsilon_{r}$.

${ }^{16}$ We do not constrain the right hand side of 4 to lie between zero and one even though the dependent variable is a proportion. The intention is to understand the explanatory power of exogenous variables on $Q u i z_{r}$.
} 
The second part of the model now uses engagement and the covariates from equation 4 to estimate the probability that respondents choose inconsistently. Table 6 shows the estimated odds ratios from the CIR models described in equation 5 . The dependent variables, $v_{r}^{f}$ were equal to one when the respondent increased allocation to $B$ (phased withdrawal) as $i$ (risk) increased or failed to move slider at least once (strong condition on consistency). Since each CIR model nests the corresponding IR model, we use a standard likelihood ratio test of the restriction implied by the IR models. The test statistics are 44.8 and 39.60 respectively. Using the conventional chi-square asymptotic distribution of this test statistic with 12 degrees of freedom (each $\boldsymbol{\beta}_{\boldsymbol{f}}$ is $13 \times 1$ ), the restriction that $\boldsymbol{\beta}_{\boldsymbol{f}}=0$ is rejected. In other words, probabilities depend on respondents' capabilities and engagement levels.

The odds ratios in Table 6 show the change in

$$
\operatorname{Pr}\left(v_{r}^{f}=1 \mid \boldsymbol{x}_{r}, Q u i z_{r}\right) /\left[1-\operatorname{Pr}\left(v_{r}^{f}=1 \mid \boldsymbol{x}_{r}, Q u i z_{r}\right)\right]
$$

of a one-unit increase in the indicated covariate. For example, for comparisons between $A$ and $B(f=1)$, the odds ratio for numeracy is 0.501 , which is significantly different from 1.0 at the $5 \%$ level. Two more correct answers in the numeracy instrument reduces the odds (equation 6) of an inconsistent allocation pattern by a factor of $0.501^{0.667}=0.631$ : if, at the lowest numeracy score of 0 , the other covariates indicate the probability of inconsistent choices is 0.50 , then the probability decreases to $0.501 /(1+0.501)=0.334$ when all three questions are answered correctly. 17

Task engagement (Quiz score) is more important than numeracy in the conditional probability of inconsistent choices. If, in a situation where the engagement score is zero (no answers correct) and the other covariates imply the probability of inconsistent choice is 0.5 , the probability of inconsistency falls to 0.06 if the engagement score rises to one (all answers correct) for a respondent allocating wealth between $A$ and $B$. The effect is still strong, though somewhat moderated, for the $C-B$ comparison, where the same probability would fall from 0.5 to 0.28 as engagement score rose from zero to one. So respondents who understand the differences between

\footnotetext{
${ }^{17}$ Existing research has established a connection between poor numeracy and mortgage defaults (Gerardi et al. 2010), inefficient consumer credit decisions (Agarwal and Mazumder 2011), lower risk tolerance, impatience, more errors in economic decisions (Burks et al. 2009) and susceptibility to framing (Peters and Levin 2008).
} 
the retirement products can make sound choices.

Surprisingly, other variables that were significant in equation 4 (i.e., financial literacy, commercial product knowledge and retirement financial planning) are not directly relevant to inconsistency rates. Only numeracy and task engagement are significant. To summarize, strong financial literacy, general financial knowledge and a tendency to plan motivate individuals to engage in the task, but it is a clear understanding of the specific features of the choice at hand, and basic numerical ability, that ultimately drives consistent retirement benefit allocations.

Table 6: Estimated odds ratios for CIR equations 5

\begin{tabular}{lcc}
\hline & $f=1$ & $f=2$ \\
\hline Quiz score & $0.117^{* *}$ & $0.401^{* *}$ \\
Gender & 1.154 & 0.796 \\
Wealth & 1.000 & 1.000 \\
Early retirement intention & 1.32 & 1.151 \\
Numeracy & $0.501^{* *}$ & $0.490^{* *}$ \\
Basic financial literacy & 1.312 & 1.115 \\
Sophisticated financial literacy & 1.130 & 0.668 \\
Self-assessed financial literacy & 0.993 & 1.019 \\
Retirement financial planning & 0.952 & 0.938 \\
Quality of life & 0.543 & 0.795 \\
Subjective life expectancy & 1.001 & 0.998 \\
& & \\
Pseudo $R^{2}$ (McFadden $)$ & 0.044 & 0.036 \\
\hline \hline
\end{tabular}

Notes: Dependent variable $v_{r}^{f}=1$ when respondent increased allocation to $B$ (phased withdrawal) as $i$ (risk) increased or failed to move slider at least once (strong condition on consistency). (1) is comparison $A-B$ and (2) is comparison $C-B$. ** Statistically significant estimated coefficient at the $5 \%$ level. * Statistically significant estimated coefficient at the $10 \%$ level. Sample size: 854 .

Although the CIR model is more general than the IR model, it still imposes the restriction that apart from the covariates included in the model, decisions over retirement income products are independent between $f=1,2$. Under this restriction, collecting further details of individual's attitudes to investment and longevity risk would be unnecessary to anyone advising on retirement financial planning. However, it is more likely that individual heterogeneity matters to decisions beyond the inventory measured by model covariates so far.

We make a formal test of the restriction that unobserved individual heterogeneity is unimportant to consistency, within the limits of the current model, by generalizing the CIR model 
to allow for conditionally dependent responses (CDR). The unrestricted model is:

$$
\operatorname{Pr}\left(v_{r}^{1}=m_{1}, v_{r}^{2}=m_{2}\right)=m_{L}\left(\boldsymbol{\gamma}, \boldsymbol{x}_{\boldsymbol{r}}, Q u i z_{r}\right),
$$

where the expression on the right side of equation 7 denotes a multinomial logit model with parameter vector $\gamma$. There are $2^{2}=4$ outcomes $\left(m_{1}, m_{2}\right)$, and so the multinomial logit model has $(4-1) \times 13=39$ coefficients. Estimates of these coefficients, reported in Table 7 are largely consistent with Table 6. Coefficients on engagement and numeracy are of a similar sign and size, though fewer are statistically significant than for the binomial logit CIR model. Other covariates remain insignificant, with one exception among the 39 estimated parameters.

Table 7: Estimated odds ratios for CDR equation7

\begin{tabular}{lccc}
\hline & consistent $f=1 \& 2$ & consistent $f=1$ & consistent $f=2$ \\
\hline Quiz score & $11.471^{* *}$ & $6.546^{* *}$ & 1.263 \\
Gender & 0.992 & 0.914 & $1.487^{* *}$ \\
Wealth & 1.000 & 1.000 & 1.000 \\
Early retirement intention & 0.723 & 0.783 & 0.943 \\
Numeracy & $3.250^{* *}$ & 1.361 & 1.556 \\
Basic Literacy & 0.827 & 0.647 & 0.819 \\
Sophisticated Literacy & 1.204 & 0.790 & 1.665 \\
Self-assessed Literacy & 1.018 & 0.948 & 0.930 \\
Retirement financial planning & 1.075 & 1.074 & 1.089 \\
Quality of life & 1.778 & 2.182 & 1.206 \\
Subjective life expectancy & 1.002 & 0.994 & 1.000 \\
& & & \\
Pseudo $R^{2}(M c F a d d e n)$ & & & 0.037 \\
\hline \hline
\end{tabular}

Notes: $v_{r}^{f}=1$ when respondent increased allocation to $B$ (phased withdrawal) as $i$ (risk) increased or failed to move slider at least once (strong condition on consistency). Group 1 are consistent in $A$ v. $B$ and $C$ v. $B$ comparisons; Group 2 are consistent in $A$ v. $B$ and inconsistent in $C$ v. $B$ comparisons; Group 3 are inconsistent in $A$ v. $B$ and consistent in $C$ v. $B$ comparisons; and reference level Group 4 are inconsistent in $A$ v. $B$ and $C$ v. $B$ comparisons. $* *$ Statistically significant estimated coefficient at the $5 \%$ level. ${ }^{*}$ Statistically significant estimated coefficient at the $10 \%$ level. Sample size: 854 .

Given any set of coefficient vectors $\boldsymbol{\beta}_{\boldsymbol{f}}$ from binomial logit CIR models, there is a coefficient vector $\gamma$ in the multinomial logit CDR model such that

$$
m_{L}(\boldsymbol{\gamma}, \boldsymbol{x}, Q u i z)=f_{L}\left(\boldsymbol{\beta}_{\mathbf{1}}, \boldsymbol{x}, \text { Quiz) } \cdot f_{L}\left(\boldsymbol{\beta}_{\mathbf{2}}, \boldsymbol{x}, \text { Quiz }\right)\right)
$$


for all possible (x, Quiz). Since the CDR model nests the CIR model, the maximum of the $\log$ likelihood function in the CDR model cannot be smaller than the sum of the maximums of the log likelihood functions in the two corresponding CIR models. The sum of the log likelihoods of the CIR models is -1022.3 compared with -981.89 for the CDR model implying a test statistic of 80.81. Using the conventional chi-square asymptotic distribution of this test statistic with 13 degrees of freedom $\left(\boldsymbol{\gamma}\right.$ is $39 \times 1$, each $\boldsymbol{\beta}_{\boldsymbol{f}}$ is $\left.13 \times 1\right)$, the hypothesis of independence across the two choice scenarios is rejected. In other words, idiosyncratic variation is still important to retirement benefit choice patterns even after allowing for an array of demographic and capability measures.

\section{Conclusion and discussion}

This paper studies the behavior of individuals as they allocate retirement wealth between a lifetime annuity and a phased withdrawal. This is an increasingly prevalent, yet complex, decision in a DC world where retirement savers bear responsibility to turn lump sum benefits into lifetime income. Most existing research assumes that people know about retirement income products and have a basic grasp of how they function. We investigate the impact of disengagement and poor understanding of products on the quality of allocations. Specifically, we measure how well retirement plan members manage an increasing risk of running out of liquid wealth before the end of life: respondents who reduce their exposure to this rising risk by maintaining or increasing annuitization turn out to be engaged respondents who know how the products work.

Our analysis of retirement benefit choices can be described as follows:

1. A large minority of respondents choose consistently with predictions of a simple CRRA utility maximization model by not increasing allocations of retirement wealth to the phased withdrawal product as the probability of exhausting it increases. The remainder increase their allocation to the phased withdrawal product even in the face of an increasing probability of permanently reducing income before the end of life. Inconsistency rates are lower where the phased withdrawal product is paired with the annuity with 15 year guarantee than where the guarantee is absent. 
2. Respondents with higher financial capability (numeracy, financial literacy, and commercial product knowledge) pay more attention to new information about the retirement products and recall that information better when tested (measured using a post task quiz). For example, two additional correct responses in the numeracy or basic financial literacy (interest and inflation) questions improve scores in a quiz on the annuity and phased withdrawal products by about one standard deviation.

3. However, financial capability is only indirectly connected with consistent choices, with only numeracy having a direct, positive impact on the likelihood of rational choices over and above its indirect effect on engagement with the choice task.

4. Task engagement (and numeracy) increase the probability that subjects will choose in a consistent manner: at maximum engagement (measured by the number of correct answers in the post task recall quiz of product features), the probability of inconsistent choices declines by $90 \%$ compared with a zero engagement score, while raising numeracy from minimum to maximum scores reduces the probability of inconsistency by around $40 \%$. Therefore, while strong financial literacy, general financial knowledge and a tendency to plan can motivate individuals to engage in the task, it is a clear understanding of the specific features of the choice at hand and basic numerical ability that enables better allocation decisions. However, tests of dependence indicate that unobserved individual heterogeneity is also important.

Our findings have several implications for policy makers and providers of retirement income products. First, while revealed preference data suggest people show scant interest in annuity products, our allocation task shows much more interest when products are described by their characteristics, rather than their commercial names. In the experiment described here, where respondents are given descriptions of products in terms of five common features (but no product names), a majority say that they would fully or partially annuitize their retirement accumulation. Revealed preference data is often used by government to support inaction in policy development and by the financial services industry to justify a lack of product innovation. Our study suggests that both government and industry need to take more care to explain the key insurance features of alternative retirement benefit products before dismissing then as not interesting to consumers. 
Second, our study tests how financial competence (numeracy and financial literacy, and commercial product knowledge) can help people understand reasonably simple retirement benefit product information. We find that those with more competence are more engaged, and the more engaged are more likely to make 'better' decisions. While we cannot unequivocally translate 'engagement' with the hypothetical task to 'real world' engagement with the retirement benefit decision, our findings do suggest improving the financial skills and product knowledge of real world retirement savers might help, as recommended in Lusardi and Mitchell (2011) and Clark et al. (2011) among others. The challenge is how to improve 'real world' financial literacy and commercial product knowledge of retirement savers through both education and improved benefit product information formats. Finally, an overall implication of this study is that disengagement with the retirement benefit decision could provide a partial solution to the annuity puzzle. 


\section{References}

Agarwal, S., Mazumder, B., 2010. Cognitive Abilities and Household Financial Decision Making. Federal Reserve Bank of Chicago Working Paper Series No 2010-16, Chicago, Illinois.

Agnew, J., Anderson, l., Gerlach, J.R., Szykman, L., 2008. Who Chooses Annuities? An Experimental Investigation of the Role of Gender, Framing, and Defaults. American Economic Review. $98,418-22$.

Australian Government Actuary., 2009. Australian Life Tables, Canberra, ACT, Department of Treasury.

Benartzi, S., Previtero, A., Thaler, R.H., 2012. Annuitization Puzzles. Journal of Economic Perspectives. 25(4),143-164.

Bernheim, B.D., 2002. Taxation and Saving, in: Auerbach, A.J., Feldstein, M., (Eds.), Handbook of Public Economics, Elsevier, 3, pp. 1173-1249.

Bernheim, B.D., 1991. How Strong Are Bequest Motives? Evidence Based on Estimates of the Demand for Life Insurance and Annuities. The Journal of Political Economy. 99(5), 899-927.

Beshears, J., Choi, J.J., Laibson, D., Madrian, B.C., 2008. How are Preferences Revealed? Journal of Public Economics 92(8-9), 1787-1794.

Beshears, J., Choi, J.J., Laibson, D., Madrian, B.C., Zeldes, S.P., 2012. What Makes Annuitization More Appealing? NBER Working Paper 18575.

Brown, J., Poterba, J., 2001. Joint Life Annuities and the Demand for Annuities for Married Couples. Journal of Risk and Insurance. 67(4), 527-553.

Brown, J.R., Kling, J.R., Mullainathan, S., Wrobel, M.V., 2008. Why Don't People Insure Late-Life Consumption? A Framing Explanation of the Under-Annuitization Puzzle. American Economic Review. 98, 418-22.

Brown, J.R., 2008. Understanding the Role of Annuities in Retirement Planning, in: Lusardi, A., (Ed.), Overcoming the Saving Slump. University of Chicago Press, Chicago, IL, 178-206.

Brown, J.R., Kapteyn, A., Mitchell, O.S., 2011. Do Consumers Know How to Value Annuities? Complexity as a Barrier to Annuitization'. RAND Financial Literacy Center Working Paper WR-924-SSA.

Burks, S.V., Carpenter, J.P., Goette, L., Rustichini, A., 2009. Cognitive skills affect economic preferences, strategic behavior, and job attachment. Proceedings of the National Association of Sciences, 106, 7745-7750.

Bütler, M., Teppa, F., 2007. The Choice between an Annuity and a Lump Sum: Results from Swiss Pension Funds. Journal of Public Economics. 91(10), 1944-1966.

Camerer, C., Hogarth, R., 1999. The Effects of Financial Incentives in Experiments: A Review and Capital-Labor Production Framework. Journal of Risk and Uncertainty. 19(1), 7-42.

Cappelletti, G., Guazarotti, G., Tommasino, P., 2011. What determines annuity demand at retirement? Bank of Italy Temi di Discussione Working Paper No. 805. 
Carroll, C., 2006. The Method of Endogenous Gridpoints for solving Dynamic Stochastic Optimization Problems. Economics Letters. 91(3), 312-320.

Clark, R., Morrill, M., Allen, S., 2009. Employer Provided Retirement Planning Programs, in: Clark, R., Mitchell, O.S., (Eds.), Reorienting Retirement Risk Management. Oxford University Press, Oxford, UK, pp. 36-64.

Clark, R., Morrill, M., Allen, S., 2011. Pension Plan Distributions: The Importance of Financial Literacy. in: Mitchell, O.S., Lusardi, A., (Eds.), Financial Literacy: Implications for Retirement Security and the Financial Marketplace, Oxford University Press, Oxford, UK.

Davidoff, T., Brown, J., Diamond, P., 2005. Annuities and Individual Welfare. American Economic Review. 95(5), 1573-1590.

Dushi, I., Webb, A., 2004. Household Annuitization Decisions: Simulations and Empirical Analyses. Journal of Pension Economics and Finance. 3(2), 109-143.

Employee Benefits Research Institute (EBRI)., 2011. EBRI Databook on Employee Benefits. http://www.ebri.org/publications/books/?fa=databook.

Gerardi, K., Goette, L., Meier, S., 2010. Financial Literacy and Subprime Mortgage Delinquency: Evidence from a Survey Matched to Administrative Data. Federal Reserve Bank of Atlanta Working Paper Series No 2010-10.

Guiso, L., Jappelli, T., 2008. Financial Literacy and Portfolio Diversification. European University Institute Working Paper, ECO 2008/31.

Gustman, A.L., Steinmeier, T.L., Tabatabai, N., 2012. Financial Knowledge and Financial Literacy at the Household Level. American Economic Review. 102(3), 309-12.

Harmer, J., 2009. Pension Review Report, 27 February 2009, Commonwealth of Australia.

Horneff, W., Maurer, R., Mitchell, O.S., Dus, I., 2007. Money in Motion: Asset Allocation and Annuitization in Retirement. NBER Working Paper 12942, National Bureau of Economic Research, Cambridge, MA. http://www.nber.org/papers/w12942.

Hu Wei-Yin., Scott, J.S., 2007. Behavioural Obstacles to the Annuity Market. Financial Analysts Journal. 63(6), 71-82.

Huang, H., Milevsky, M.A., Wang, J., 2004. Ruined Moments in your Life: How Good are the Approximations? Insurance: Mathematics and Economics, 34, 421-447.

Inkmann, J., Lopes, P., Michaelides, A., 2011. How Deep Is the Annuity Market Participation Puzzle? Review of Financial Studies 24(1), 279-319.

Kamis, A., Koufaris, M., Stern, T., 2008. Using an Attribute-based DSS for User-customized Products online: An Experimental Investigation. MIS Quarterly 32(1), 159-177.

Kingston, G., Thorp, S., 2005. Annuitization and Asset Allocation with HARA Utility. Journal of Pension Economics and Finance. 4(3), 225-248.

Lipkus, I.M., Samsa, G., Rimer, B.K., 2001. General Performance on a Numeracy Scale among Highly Educated Samples. Medical Decision Making 21(1), 37-44. 
Lusardi, A., Mitchell, O.S, 2009. How Ordinary Consumers Make Complex Economic Decisions: Financial Literacy and Retirement Readiness. NBER Working Paper w15350, National Bureau of Economic Research, Cambridge, MA.

Lusardi, A., Mitchell, O.S., 2011. Financial Literacy around the World: An Overview. Journal of Pension Economics and Finance. 10(4), 497-508.

Milevsky, M., Young, V., 2007. Annuitization and Asset Allocation. Journal of Economic Dynamics and Control. 31(9), 3138-3177.

Mitchell, O.S., Piggott, J., Takayama, T., 2011. Turning Wealth into Lifetime Income: The Challenge Ahead, in: Mitchell, O.S., Piggott, J., Takayama, N., (Eds.), Securing Lifelong Retirement Income: Global Annuity Markets and Policy, Oxford University Press, pp. 1-9.

Mitchell, O.S., Poterba, J.M., Warshawsky, M.J., Brown, J.R., 1999. New Evidence on the Money's Worth of Individual Annuities. American Economic Review. 89(5), 1299-1318.

Oppenheimer, D.M., Meyvis, T., Davidenko, N., 2009. Instructional Manipulation Checks: Detecting Satisficing to Increase Statistical Power. Journal of Experimental Social Psychology. 45, 867-872.

Peijnenburg, K., Nijman, T., Werker, B., 2010. Health Cost Risk and Optimal Retirement Provision: A Simple Rule for Annuity Demand. Pension Research Council Working Paper No. WPS 2010-08.

Peters, E., Levin, I.P., 2008. Dissecting the Risky-choice Framing Effect: Numeracy as an Individual-difference Factor in Weighting Risky and Riskless Options. Judgement and Decision Making. 3, 435-448.

Plan For Life., 2012. The Pension and Annuity Market Research Report, Mt. Waverly, VIC: Plan For Life Actuaries and Researchers.

Turra, C., Mitchell, O.S., 2008. The Impact of Health Status and Out-of-Pocket Medical Expenditures on Annuity Valuation, in: Ameriks, J., Mitchell, O.S., (Eds.) Recalibrating Retirement Spending and Saving, Oxford University Press, Oxford, UK.

Yaari, M., 1965. Uncertain Lifetime, Life Insurance, and the Theory of the Consumer. Review of Economic Studies. 32, 137-150. 


\section{Appendix A}

\section{Age Pension regulations}

The Age Pension benefit $p_{t}$ is

$$
p_{t}\left(M_{t}\right)=\max \left(0, F P-\max \left(I T_{t}, A T_{t}\right)\right),
$$

where $F P$ is the maximum payment, assumed constant in the model, and $I T_{t}$ and $A T_{t}$ are reductions due to income and asset tests respectively. At the time of the experiment, the maximum annual payment was $\$ 18,961.80$ for single pensioners.

The income test induces a $50 \%$ offset in the maximum payment for every dollar received above a certain threshold $(\overline{I T})$. Different sources of income $(I)$ are treated differently for the purpose of the income test, so that returns to financial investments are deemed at a fixed progressive rate, while incomes from long-term income stream products (including annuities) are reduced by returns of capital. The asset test induces a $3.9 \%$ offset in in the maximum payment for every dollar in assets above a certain threshold $(\overline{A T})$. For the purposes of this test, financial assets are assessed at their market value, and income stream products are assessed at their residual value. The exact formulas for income and asset tests are

$$
\begin{gathered}
I T_{t+1}=\max \left\{0, \frac{1}{2}\left(I_{t+1}-\overline{I T}\right)\right\}, \\
I_{t+1}=D R_{2}\left(M_{t}-c_{t}\right)-\left(D R_{2}-D R_{1}\right) \min \left\{\left(M_{t}-c_{t}\right), \overline{D R}\right\}+\left(y-\frac{p_{A} w}{L E_{1}}\right),
\end{gathered}
$$

where for simplicity we are treating investable wealth as financial investments and $L E_{1}$ is life expectancy at time $t=1$. Deeming rates at the time of the experiment were $D R_{1}=3 \%$ and $D R_{2}=4.5 \%, \overline{I T}=43,200.00 A \$, \overline{D R}=3,796.00 A \$$ for singles.

$$
A T_{t+1}=\max \left\{0,0.039\left(\tilde{R}\left(M_{t}-c_{t}\right)+p_{A} w \cdot \max \left\{0,\left(1-\frac{t}{L E_{1}}\right)\right\}-\overline{A T}\right)\right\},
$$

where $\overline{A T}=181,750.00 A \$$ p.a. for singles.

Under the assumption of no labor income, both tests in (8) depend primarily on the previous period's wealth, $M_{t}-c_{t}$, and the annuity component of the portfolio, $p_{A}$. Because the annuity provides lower assessable income (under the income test) and is counted only at a fraction of its purchase price (under the asset test), allocating more of the retirement wealth to the annuity shifts both income and asset test tapers to the right, resulting in higher public Age Pension for a given amount of initial wealth. (See Figure 3.) 


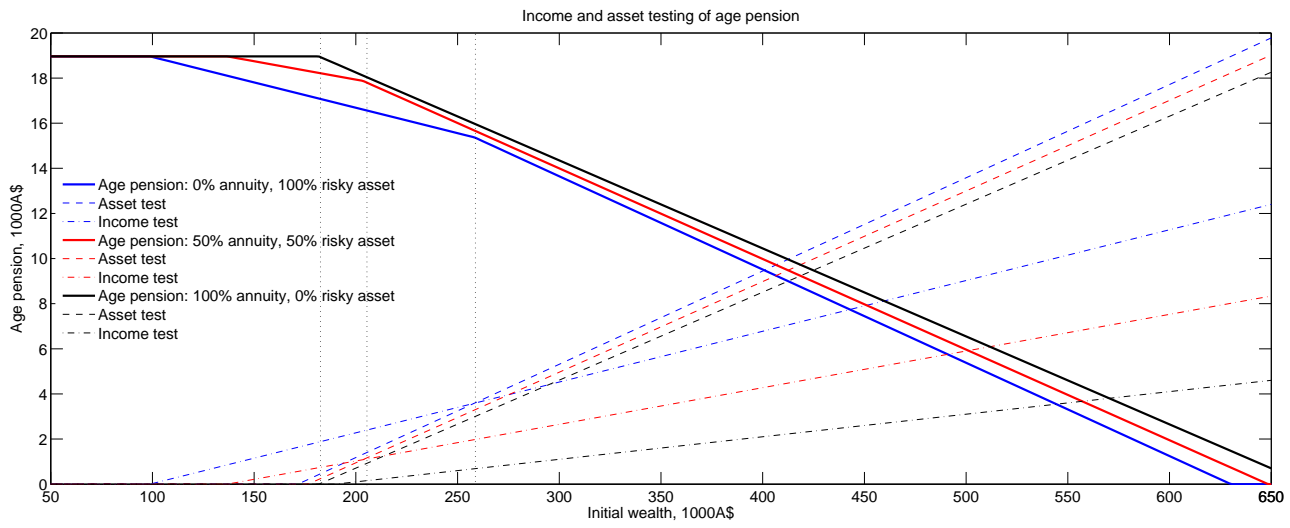

Figure 3: Age pension benefits and means testing for single individuals as function of pension wealth $w, 1000 \mathrm{~A} \$$.

\section{Appendix B}

\section{Experiment instructions}

"In the next few questions we will ask you to complete $\mathbf{4}$ sets of choice tasks about $\mathbf{2}$ financial products.

On leaving the workforce, most people need to use money from their superannuation and other savings to cover their spending. Industry and Government are looking for simple financial products to help Australians manage their superannuation and savings during retirement.

The retirement income products we are going to show you are designed by large financial firms, like insurance companies and superannuation funds, to cover spending and manage financial risks in retirement.

\section{Product A: Get a guaranteed income.}

- Who provides this product?

- It is supplied by large life insurance firms. These firms have to meet strict government regulations to be allowed to sell this product.

- How much income will I receive?

- You will receive a fixed regular income.

- How long do payments last?

- You will receive the regular income for as long as you live, regardless of how long or short that is.

- What happens if I die?

- If you die, payments stop.

- Can I withdraw a lump sum for unforeseen events or changes of plans?

- No. To purchase this product, you pay a lump sum to the insurance firm in exchange for the income stream and you cannot get it back. Your beneficiaries do not get the lump sum back if you die. 


\section{Product B: Withdraw a regular income.}

- Who provides this product?

- It is supplied by superannuation funds. Your money is held in an account and invested in financial assets like shares and bonds.

- How much income will I receive?

- You can decide how much of your balance to withdraw each year. Your account balance will fluctuate each year with financial markets. You will pay fees each year to the fund that manages your account.

- How long do payments last?

- There is no guarantee you will have a lifetime income. How long payments last depends on investment returns, fees and your withdrawals.

- What happens if I die?

- If you die, remaining money in your account goes to your dependents or your estate.

- Can I withdraw a lump sum for unforeseen events or changes of plans?

- Yes. You can take all or a part of any remaining money out, but if you do it will not be available to pay you income in the future."

Respondents were then shown several examples of the product configurator and completed four choices. After that they saw another screen: "Thank you for completing the last 4 tasks. Now we want you to compare Product B with a different type of guaranteed income product in another 4 similar tasks.

Product C: Get a guaranteed income with a fixed term payment period.

- Who provides this product?

- It is supplied by large life insurance firms. These firms have to meet strict government regulations to be allowed to sell this product.

- How much income will I receive?

- You or your beneficiaries will receive a fixed regular income.

- How long do payments last?

- You personally will receive the regular income for as long as you live, regardless of how long or short that is. If you die within the fixed term period, the regular income continues to be paid to your beneficiaries or estate up to the end of the 15 th year.

- What happens if I die?

- Payments are guaranteed to you or your beneficiaries for the first 15 years, even if you die within that period. Payments are guaranteed only to you after that time.

- Can I withdraw a lump sum for unforeseen events or changes of plans?

- No. To purchase this product, you pay a lump sum to the insurance firm in exchange for the income stream and you cannot get it back. Your beneficiaries do not get the lump sum back if you pass away." 


\section{Appendix $\mathrm{C}$}

\section{Life expectancy/current age:}

- To what age do you think you will live?

- What is your current age?

\section{Financial aspects of retirement planning question:}

- Which of the following statements best describes your thoughts about the financial aspects of retirement?

1. I haven't thought at all about what I will need for retirement

2. I have just started to think about what I will need in terms of savings for retirement, but haven't checked out my current financial position.

3. I have thought about it a fair bit, and have checked out my current financial position.

4. I have some firm ideas about what I will need and have compared my current position with my idea of what I will need.

5. I have a firm idea of what I need but I'm not sure if I can reach it, and haven't planned a way to get there.

6. I have a firm idea of what I need, I'm not sure if I can reach it, but I have planned a way to get there.

7. I have a firm idea of what I need and I'm on track to reach it.

\section{Quality of Life questions:}

- Mobility

1. I am confined to bed

2. I have SOME PROBLEMS walking around

3. I have NO PROBLEMS walking around

- Self-care

1. I CANNOT wash or dress myself

2. I have SOME PROBLEMS washing or dressing myself

3. I have NO PROBLEMS with self-care

- Activities

1. I CANNOT do my usual activities

2. I have SOME PROBLEMS doing my usual activities

3. I have NO PROBLEMS doing all my usual activities

- Pain/Discomfort

1. I have A LOT of pain or discomfort

2. I have MODERATE pain or discomfort

3. I have NO pain or discomfort 
- Anxiety/Depression

1. I'm VERY anxious or depressed

2. I'm MODERATELY anxious or depressed

3. I'm NOT anxious or depressed

\section{Self-assessed financial literacy}

- On a scale of 1 to 7 , where 1 means very low and 7 means very high, how would you assess your understanding of finance?

\section{Numeracy:}

- Imagine that we rolled a fair, six-sided die 1,000 times. Out of 1,000 rolls, how many times do you think the die would come up with even numbers?

- In a lottery, the chance of winning a $\$ 10$ prize is $1 \%$. What is your best guess about how many people would win a $\$ 10$ price if 1,000 people each buy a single ticket to the lottery.

- In a raffle, the chance of winning a car is 1 in 1,000 . What percent of tickets in the raffle win a car?

\section{Financial Literacy:}

- Suppose you had $\$ 100$ in a savings account and the interest rate was $2 \%$ per year. After 5 years how much do you think you would have in the account if you left the money to grow?

- Imagine that the interest rate on your savings account was $1 \%$ per year and inflation was $2 \%$ per year. After 1 year, how much would you be able to buy with the money in this account?

- When an investor spreads his money among different assets, does the risk of losing money?

- Please tell me whether this statement is true or false. 'Buying a single company's shares usually provides a safer return than a share managed fund.'

\section{Commercial product knowledge}

Respondents were asked the following:

Below is a list of features for products. For each product listed..., please select all product features that you think apply to each product. Please select all that apply for each product... that you have heard of.

The products surveyed were:

- Allocated (or account-based) pension

- Lifetime annuity

- Term certain annuity

- CPI Indexed lifetime annuity

- Single lifetime annuity with reversion 
- Guaranteed lifetime annuity

- Transition to retirement pension

- None of these

The features surveyed were:

- To purchase this product, I pay a lump sum of my capital and do not get it back.

- My capital is tied up for a fixed term.

- My account balance will go up and down with the financial markets.

- I can choose the amount of income I withdraw, as long as I withdraw the minimum required by the government.

- I can withdraw my capital/ balance at any time or leave it to someone in my will.

- The dollar amount of my capital is guaranteed not to go down.

- I can choose where my money is invested.

- The dollar amount of my income is guaranteed not to go down.

- My income is guaranteed to increase with inflation.

- The value of my capital is guaranteed to increase with inflation.

- Income from this product lasts my whole life regardless of how long I live.

- If I die, my partner can receive the income from this product.

- If I die, my partner or beneficiaries can receive the capital/balance from this product.

\section{Consistency definitions used are:}

1. Non-increasing allocation to the phased withdrawal product $B$ for all four choices in $A$ versus $\mathrm{B}$ and move the slider at least once (1).

2. Non-increasing allocation to the phased withdrawal product $B$ for all four choices in $\mathrm{C}$ versus $B$ and move the slider at least once (2). 